\title{
Early cardiac hypertrophy in mice with impaired calmodulin regulation of cardiac muscle $\mathrm{Ca}^{2+}$ release channel
}

Naohiro Yamaguchi, ${ }^{1}$ Nobuyuki Takahashi, ${ }^{2}$ Le Xu, ${ }^{1}$ Oliver Smithies, ${ }^{2}$ and Gerhard Meissner ${ }^{1}$

${ }^{1}$ Department of Biochemistry and Biophysics and 2Department of Pathology and Laboratory Medicine, School of Medicine, University of North Carolina at Chapel Hill, Chapel Hill, North Carolina, USA.

\begin{abstract}
Studies with isolated membrane fractions have shown that calmodulin (CaM) inhibits the activity of cardiac muscle cell $\mathrm{Ca}^{2+}$ release channel ryanodine receptor 2 (RyR2). To determine the physiological importance of $\mathrm{CaM}$ regulation of RyR2, we generated a mouse with 3 amino acid substitutions (RyR2-W3587A/L3591D/ F3603A) in exon 75 of the Ryr2 gene, which encodes the CaM-binding site of RyR2. Homozygous mutant mice showed an increased ratio of heart weight to body weight, greatly reduced fractional shortening of the left ventricle, and lethality at 9-16 days of age. Biochemical analysis of hearts of 7- and 10-day-old homozygous mutant mice indicated an impaired $\mathrm{CaM}$ inhibition of $\mathrm{RyR} 2$ at micromolar $\mathrm{Ca}^{2+}$ concentrations, reduction in $\mathrm{RyR} 2$ protein levels and sarcoplasmic reticulum $\mathrm{Ca}^{2+}$ sequestration, and upregulation of genes and/or proteins associated with class II histone deacetylase/myocyte enhancer factor-2 and calcineurin signaling pathways. Sustained $\mathrm{Ca}^{2+}$ transients, often displaying repeated periods of incomplete $\mathrm{Ca}^{2+}$ removal, were observed in homozygous cardiomyocytes. Taken together, the data indicate that impaired CaM inhibition of RyR2, associated with defective sarcoplasmic reticulum $\mathrm{Ca}^{2+}$ release and altered gene expression, leads to cardiac hypertrophy and early death.
\end{abstract}

\section{Introduction}

Calmodulin (CaM) is a small cytoplasmic $\mathrm{Ca}^{2+}$ binding protein that regulates numerous cellular activities. CaM may exert its action through a direct interaction with its target proteins or indirectly by regulating the activity of $\mathrm{Ca}^{2+} / \mathrm{CaM}$-dependent protein kinase, and CaM stimulated protein phosphatase (calcineurin) (1, 2). In cardiac muscle, CaM modulates, directly or indirectly, the activity of proteins that play a key role in the release and subsequent sequestration of cytosolic $\mathrm{Ca}^{2+}$ back into the sarcoplasmic reticulum (SR). Three target proteins are the voltage- and dihydropyridine-sensitive surface membrane L-type $\mathrm{Ca}^{2+}$ channel $\left(\mathrm{Ca}_{v} 1.2\right)$ $(3,4)$, cardiac muscle cell $\mathrm{Ca}^{2+}$ release channel ryanodine receptor 2 (RyR2) $(2,5)$, and SR $\mathrm{Ca}^{2+}$ ATPase-associated (SERCA2a-associated) protein phospholamban (6). During an action potential, the entry of $\mathrm{Ca}^{2+}$ through the L-type $\mathrm{Ca}^{2+}$ channel triggers the massive release of $\mathrm{Ca}^{2+}$ from the SR by opening $\mathrm{Ca}^{2+}$-gated RyR2 ion channels. The released $\mathrm{Ca}^{2+}$ initiates muscle contraction. The subsequent sequestration of released $\mathrm{Ca}^{2+}$ back into the SR by SERCA2a leads to muscle relaxation.

The cardiac $\mathrm{Ca}^{2+}$ release channel is comprised of four $560-\mathrm{kDa}$ RyR2 subunits, four 12.6-kDa FK506-binding protein subunits, and various associated proteins that include $\mathrm{Ca}^{2+} / \mathrm{CaM}$-dependent protein kinase II (CaMKII), calcineurin, and CaM (5, 7-9). A bimodal dependence of RyR2 activity on the physiological activator $\mathrm{Ca}^{2+}$ suggests the presence of high-affinity (micromolar) activating and low-affinity (millimolar) inhibitory $\mathrm{Ca}^{2+}$ binding sites.

Nonstandard abbreviations used: ADA, W3587A/L3591D/F3603A; CaM, calmodulin; CaMKII, $\mathrm{Ca}^{2+} / \mathrm{CaM}$-dependent kinase II; HDAC, histone deacetylase; MEF2, myocyte enhancer factor-2; MCIP1, myocyte-enriched calcineurin-interacting protein 1; RyR2, ryanodine receptor 2; SR, sarcoplasmic reticulum; SERCA2a, SR Ca ${ }^{2+}$ ATPase. Conflict of interest: The authors have declared that no conflict of interest exists. Citation for this article: J. Clin. Invest. 117:1344-1353 (2007). doi:10.1172/JCI29515
CaM inhibits $\mathrm{Ca}^{2+}$-gated RyR2 activity by binding to a single site highly conserved among the RyRs (10). In single-channel measurements, CaM lowered RyR2 channel open probability from low micromolar to submicromolar $\mathrm{Ca}^{2+}$ concentrations by decreasing the number of channel events and increasing the duration of close times (11). These data have suggested that CaM provides a complementary mechanism for regulating $\mathrm{SR} \mathrm{Ca}^{2+}$ release in addition to the regulation of RyR2 by $\mathrm{Ca}^{2+}$. The physiological importance of regulation of RyR2 by CaM, however, is not well understood.

To explore the role of CaM regulation of RyR2 in vivo, we generated a mouse model with 3 amino acid replacements (RyR2W3587A/L3591D/F3603A [RyR2ADA]) in the Ryr2 gene that was hypothesized to impair CaM regulation of RyR2 in vivo. We assessed the effects of impaired CaM regulation of RyR2 on animal survival, cardiac function, $\mathrm{SR} \mathrm{Ca}^{2+}$ release and sequestration, and expression of genes associated with cardiac hypertrophy. The results show that impaired CaM regulation of RyR2 is associated with an abnormal SR $\mathrm{Ca}^{2+}$ release and altered gene regulation, which lead to cardiac hypertrophy and early death of the homozygous mutant $\left(R y r 2^{A D A / A D A}\right)$ mice.

\section{Results}

CaM regulates multiple cellular functions. We have previously shown that deletion of amino acid residues 3583-3603 eliminated $\mathrm{CaM}$ binding and $\mathrm{CaM}$ regulation of the cardiac ryanodine receptor ion channel (RyR2) in vitro (10). In the present study, we generated a mouse with 3 amino acid substitutions (RyR2 ${ }^{\mathrm{ADA}}$ ) in the CaM-binding domain to attenuate CaM regulation of RyR2 by gene targeting (Supplemental Figures 1-3; supplemental material available online with this article; doi:10.1172/JCI29515DS1).

$R y R 2^{A D A}$ is associated with cardiac hypertrophy and early death of homozygous mutant mice. Homozygous expression of RyR $2^{\mathrm{ADA}}$ resulted in larger hearts compared with WT at day 10 (Figure 1A). Body weight 
A
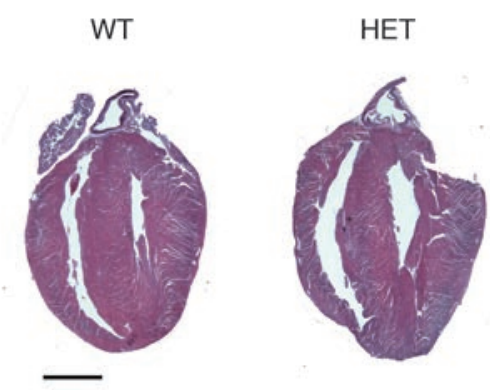
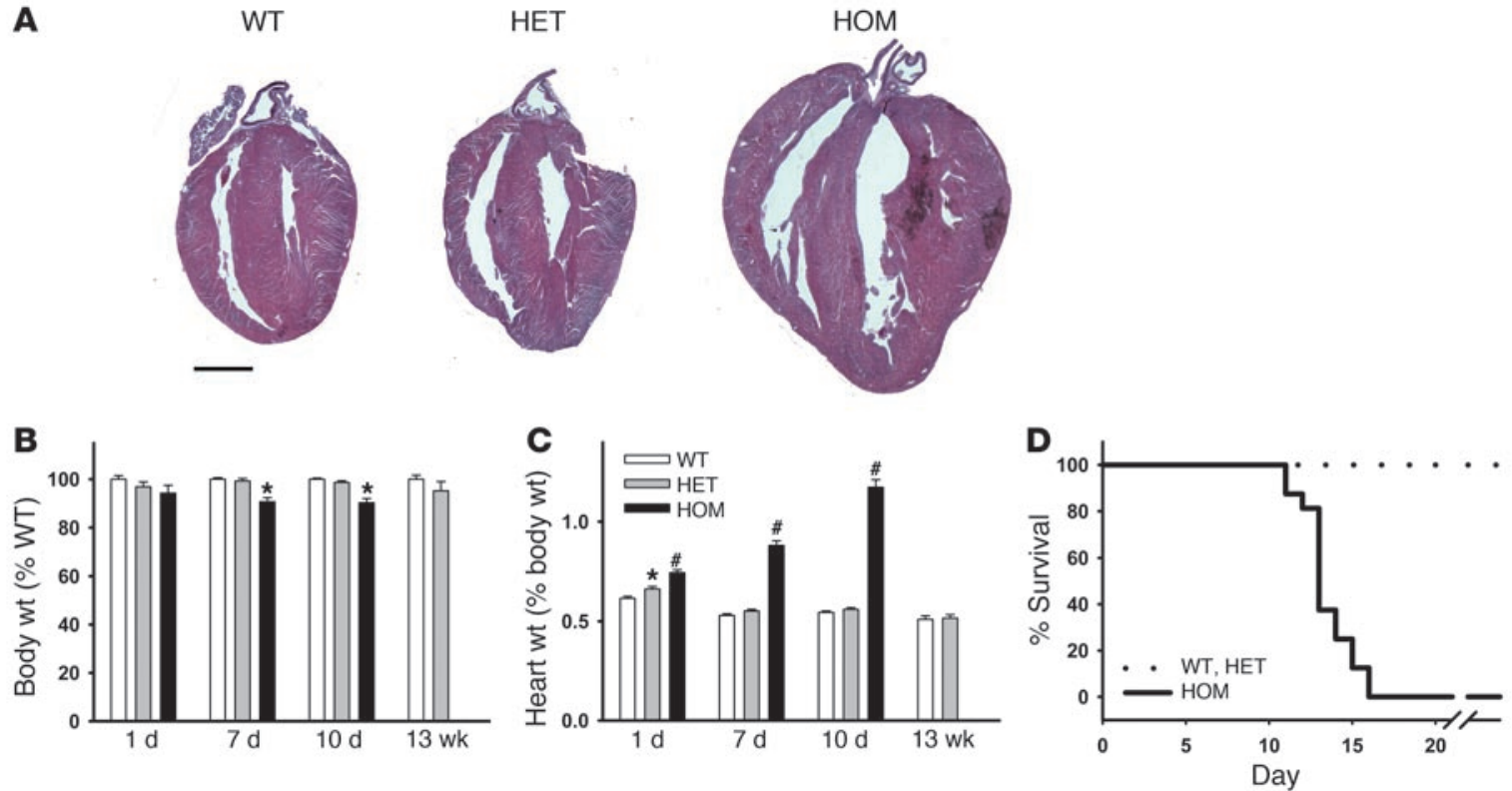

\section{Figure 1}

Body weights, heart weight to body weight ratios, and survival of WT and mutant mice. (A) H\&E-stained heart sections of 10-day-old WT and mutant mice. Scale bar: $1 \mathrm{~mm}$. (B) Body weights and (C) heart weight to body weight ratios of WT and mutant mice. Data are mean \pm SEM of 25-150 (1- to 10-day-old) or 11-14 (13-week-old) mice. ${ }^{*} P<0.05, " P<0.0001$ compared with WT. (D) Survival of WT and mutant mice after 10 days. Data for 10 WT, 15 heterozygous (HET), and 14 homozygous (HOM) mice are shown. The mean survival of homozygous mice was $13.6 \pm 0.4$ days.

was reduced by about $10 \%$ in 7 - and 10 -day-old homozygous mutant mice compared with that of WT mice, without a noticeable change in 1-day-old mice (Figure 1B). One-day-old homozygous mutant mice exhibited 1.2 times higher ratio of heart weight to body weight compared with WT mice, which became progressively higher ratios of 1.7 and 2.2 for 7- and 10-day-old mice, respectively (Figure 1C). There was a small but significant difference between heart weight/ body weight ratios of heterozygous $\left(R y r 2^{+/ A D A}\right)$ and WT mice at day 1 but no difference at days 7 and 10 (Figure 1C). Homozygous mice at day 10 displayed no obvious symptoms in other tissues. Lung/ body and liver/body weight ratios were indistinguishable among the 3 genotypes at day 10, and histological analyses of the 2 tissues showed no discernible abnormalities (not shown).

The mutations did not cause prenatal death, as heterozygous matings produced 3 genotypes of neonates close to the expected Mendelian ratio (WT, 25\% [ $n=274]$; heterozygous, 53\% $[n=586]$; homozygous, $22 \%[n=245]$ ). However, homozygous mutant mice started to die at day 9 or 10 (10 of 117 mice that lived longer than 7 days). Thus, a majority of mice were analyzed at day 10 and earlier. Of 14 homozygous mutant mice that survived to 10 days, none survived beyond 16 days (Figure 1D). Heterozygous mice were indistinguishable from WT in lifespan. Taken together, the results indicated that homozygous mutant mice developed cardiac hypertrophy by at least 1 day after birth.

Histological examination supported the development of cardiac hypertrophy in homozygous mice. Inspection of hearts of 10-dayold Ryr $2^{A D A} / A D A$ mice suggested increase in cross-sectional area of left ventricular cardiomyocytes (Figure 2, A and B). A less pronounced increase in cross-sectional area was observed in septal and right ventricular myocytes. Heterozygous mice exhibited a small but significant decrease in cross-sectional area of septal and left ventricular cardiomyocytes. Masson trichrome staining revealed the presence of collagen deposits, which suggested a modest degree of fibrosis in left ventricular tissue of 10-day-old homozygous mice (Figure 2C). An abundant accumulation of collagen was observed in papillary muscle of 10-day-old homozygous mice (Figure 2D).

The above results suggest that an impaired CaM regulation of RyR2 leads to severe left ventricular hypertrophy. To confirm this, we determined the levels of expression of 3 genes associated with cardiac hypertrophy (12-14). Quantitative RT-PCR showed that the mRNA levels of $\beta$-myosin heavy chain $(\beta-\mathrm{MHC})$, atrial natriuretic peptide, and brain natriuretic peptide (BNP) were upregulated in left ventricle of 7- and 10-day homozygous hearts (Figure 3). A significant upregulation of $\beta$-MHC and BNP was already observed in hearts of 1-day-old homozygous mice, which suggests that cardiac remodeling starts before 1 day of age, in agreement with an increase of heart weight/body weight ratio at 1 day of age (Figure 1C).

Echocardiography and electrocardiography of wild type and mutant mice. To determine whether the RyR2 ${ }^{\mathrm{ADA}}$ mutation altered cardiac function, we performed echocardiography and electrocardiography on conscious animals. The heart rate of 7- and 10-day-old Ryr2 ${ }^{A D A} / A D A$ mice was significantly slower than that of WT mice $(431 \pm 22$ versus $599 \pm 16$, and $461 \pm 19$ versus $598 \pm 21 \mathrm{bpm}$, respectively, Table 1). Both left ventricular end-diastolic and -systolic dimensions were significantly larger in homozygous mouse hearts than in WT mouse hearts (Figure 4A). Significantly reduced fractional shortening $(P<0.001)$ obtained from these 2 parameters indicated progressively exacerbating cardiac function in 7 - and 10-day homozygous hearts compared with WT hearts. Interventricular septum thickness was decreased in homozygous hearts, whereas left ventricular posterior wall thickness of homozygous hearts did 

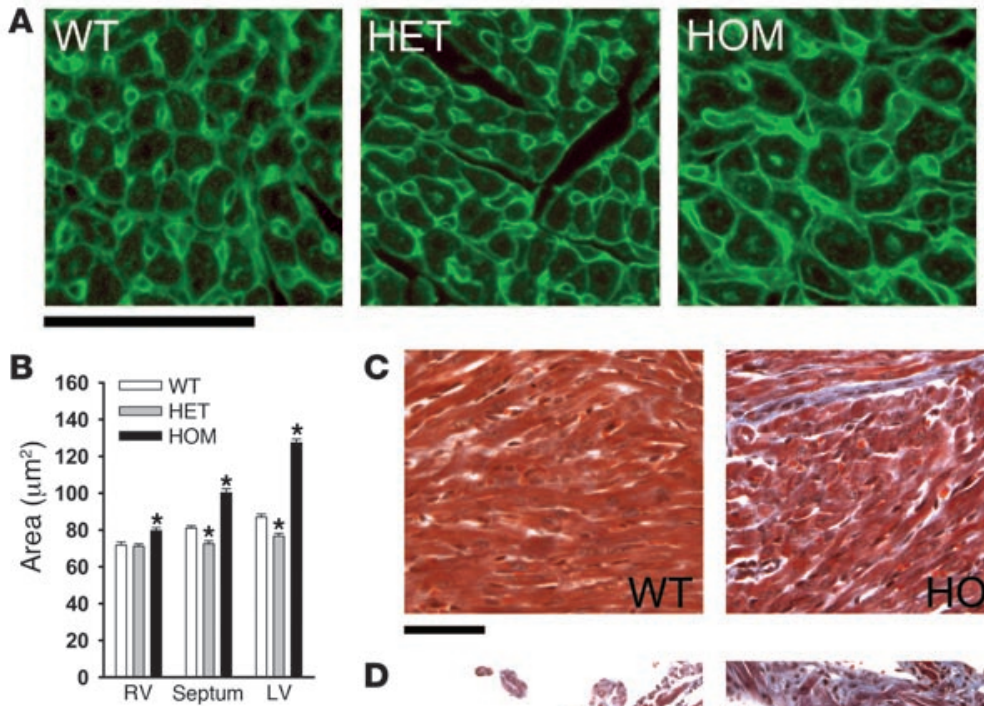

C
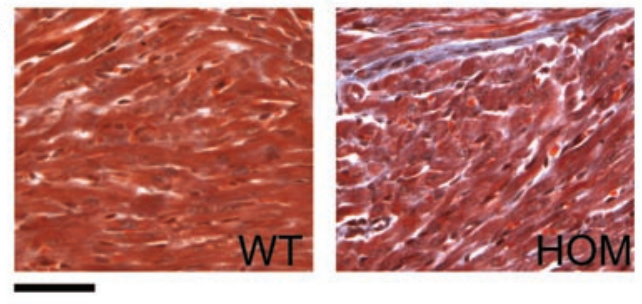

D
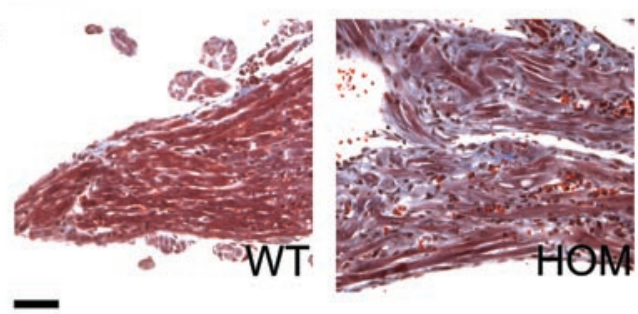

\section{Figure 2}

Histological analysis of WT and homozygous mice. (A) Heart sections were stained with TRITC-conjugated wheat germ agglutinin to outline cell borders (green pseudocolor). Left ventricles of 10-day-old mice are shown. (B) Cross-sectional areas of cardiomyocytes ( $n=250$ for each genotype) from 5 different hearts were measured. ${ }^{*} P<0.01$ compared with WT. Cells were selected randomly by a person who was blinded to genotype. In each of 5 heart cross-sections, areas of left ventricle in homozygous mice were significantly larger that those in WT mice. (C and D) Masson trichromestained left ventricle muscle (C) and papillary muscle (D) of 10-day-old mice are shown. Scale bars: $50 \mu \mathrm{m}$. not substantially differ from that of WT hearts (Table 1). None of left ventricular parameters of heterozygous mice were significantly different from those of WT mice. Taken together, these results indicate that by 7 and 10 days of age, cardiac hypertrophy is associated with ventricular dysfunction of Ryr $2^{A D A} / A D A$ mice.

Representative electrocardiogram recordings of 10 -day-old WT and homozygous mutant mice are shown in Figure 4B. Electrocardiogram of homozygous mice showed atypical recordings and significantly slower heart rates compared with WT mice $(457 \pm 21$ versus $590 \pm 25 \mathrm{bpm} ; n=6-7 ; P<0.05)$, consistent with results of echocardiography.

CaM binding and regulation of RyR2 isolated from hearts of WT and mutant mice. CaM binding to solubilized RyR2 was analyzed by CaM-Sepharose pull-down and Western blot. Figure 5A shows that RyR2s isolated from WT and heterozygous hearts bound to CaM in the presence of $900 \mu \mathrm{M} \mathrm{Ca}^{2+}$. Exogenously added CaM $(2 \mu \mathrm{M})$ greatly reduced the amount of bound RyR2, which confirmed the specificity of CaM binding to RyR2. In agreement with results of recombinant RyR2s expressed in HEK293 cells (Supplemental Figure 1), no specific CaM binding to RyR2 from homozygous hearts was observed. The efficacy of the RyR2 $2^{\mathrm{ADA}}$ mutation in eliminating CaM regulation of RyR2 in cardiomyocytes was probed, using the RyR-specific probe ryanodine (15). In initial experiments, we determined maximal $\left[{ }^{3} \mathrm{H}\right]$ ryanodine binding capacity $\left(\mathrm{B}_{\max }\right)$ values of $\left[{ }^{3} \mathrm{H}\right]$ ryanodine binding in crude membrane fractions representative of the total particulate matter (Table 2). Homozygous expression of RyR2 $2^{\mathrm{ADA}}$ in hearts of 7- and 10-day-old, but not 1-day-old, mice was associated with significantly reduced $B_{\max }$ values of $\left[{ }^{3} \mathrm{H}\right]$ ryanodine binding, which suggests a lower RyR2 protein concentration in 7- and 10-day Ryr2 ${ }^{A D A / A D A}$ hearts as compared with $\mathrm{Ryr}^{+/+}$hearts (Table 2). A small but significant decrease $(P<0.05)$ in $\mathrm{B}_{\max }$ of $\left[{ }^{3} \mathrm{H}\right]$ ryanodine binding was also observed with 10-day Ryr2 $2^{+/ A D A}$ compared with WT hearts. However, as shown in Figure $5 \mathrm{~B}$, in the absence of CaM, the ADA mutation in RyR2 did not significantly alter the $\mathrm{Ca}^{2+}$ dependence of $\left[{ }^{3} \mathrm{H}\right]$ ryanodine binding to membranes isolated from hearts of 7-day-old mice. Figure 5C shows that at $1.2 \mu \mathrm{M}$ free $\mathrm{Ca}^{2+}$, addition of physiological (50-75 $\mathrm{nM}$; refs. 16,17$)$ concentration of CaM decreased $\left[{ }^{3} \mathrm{H}\right]$ ryanodine binding to membranes prepared from $\mathrm{Ryr}^{+/+}$and $\mathrm{Ryr2} \mathrm{2}^{+/ A D A}$ hearts, whereas only a small but significant $(P<0.05)$ decrease of
Figure 3

Quantitative RT-PCR analysis of marker genes for cardiac hypertrophy. RT-PCR analyses were performed using total RNA isolated from left and right ventricles of 1-day-old mice and left ventricle of 7- and 10-dayold mice. RNA transcription levels were normalized to those of WT for each of 3 genes. ANP, atrial natriuretic peptide; $\mathrm{BNP}$, brain natriuretic peptide; $\beta$-MHC, $\beta$-myosin heavy chain. Data are the mean \pm SEM of 8-10 samples. ${ }^{*} P<0.05,{ }^{\#} P<0.001$ compared with WT.
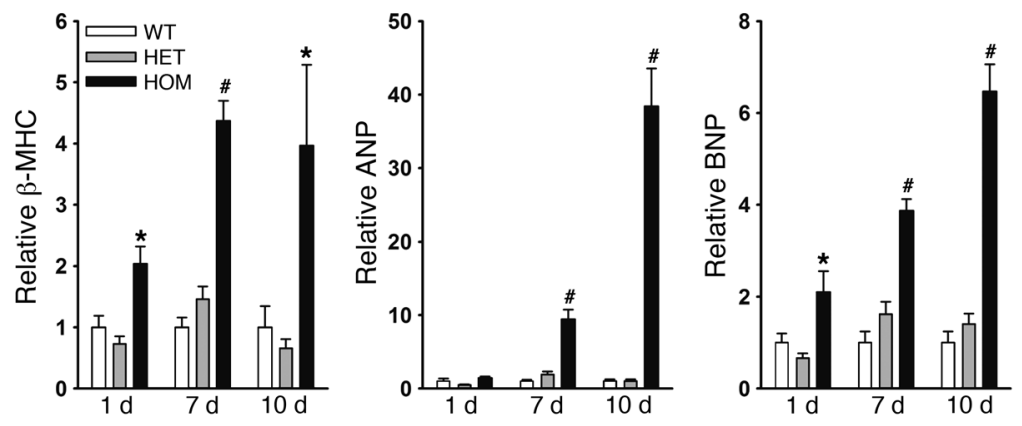
Table 1

Echocardiography in WT and mutant mice

\begin{tabular}{|c|c|c|c|c|c|c|}
\hline \multirow[b]{2}{*}{ Parameters } & \multicolumn{3}{|c|}{7 days old } & \multicolumn{3}{|c|}{10 days old } \\
\hline & WT & HET & HOM & WT & HET & HOM \\
\hline $\mathrm{HR}$ (bpm) & $599 \pm 16$ & $569 \pm 11$ & $431 \pm 22^{\mathrm{A}}$ & $598 \pm 21$ & $585 \pm 10$ & $461 \pm 19 A$ \\
\hline LVEDD (mm) & $1.57 \pm 0.09$ & $1.65 \pm 0.05$ & $2.66 \pm 0.16^{A}$ & $1.83 \pm 0.15$ & $1.91 \pm 0.10$ & $3.19 \pm 0.23^{A}$ \\
\hline LVESD (mm) & $0.67 \pm 0.07$ & $0.81 \pm 0.04$ & $2.15 \pm 0.17^{\mathrm{A}}$ & $0.73 \pm 0.10$ & $0.82 \pm 0.08$ & $2.80 \pm 0.29 \mathrm{~A}$ \\
\hline $\mathrm{FS}(\%)$ & $57.6 \pm 3.0$ & $50.9 \pm 2.4$ & $19.1 \pm 3.1^{\mathrm{A}}$ & $61.3 \pm 3.0$ & $57.3 \pm 2.9$ & $13.0 \pm 3.6^{A}$ \\
\hline IVSD (mm) & $0.74 \pm 0.05$ & $0.70 \pm 0.06$ & $0.65 \pm 0.07$ & $0.99 \pm 0.06$ & $0.91 \pm 0.08$ & $0.79 \pm 0.07$ \\
\hline IVSS (mm) & $1.10 \pm 0.07$ & $1.08 \pm 0.04$ & $0.83 \pm 0.05^{B}$ & $1.33 \pm 0.07$ & $1.27 \pm 0.08$ & $0.93 \pm 0.03^{B}$ \\
\hline LVPWD (mm) & $0.65 \pm 0.08$ & $0.61 \pm 0.05$ & $0.76 \pm 0.08$ & $0.68 \pm 0.07$ & $0.76 \pm 0.07$ & $0.96 \pm 0.08$ \\
\hline LVPWS (mm) & $1.02 \pm 0.08$ & $0.90 \pm 0.03$ & $0.87 \pm 0.07$ & $1.08 \pm 0.08$ & $1.20 \pm 0.05$ & $1.01 \pm 0.07$ \\
\hline
\end{tabular}

FS, fractional shortening ([LVEDD - LVESD]/LVEDD); HET; heterozygous; HOM, homozygous; HR, heart rate; IVSD, interventricular septum diastolic thickness; IVSS, interventricular septum systolic thickness; LVEDD, left ventricular end-diastolic dimension; LVESD, left ventricular end-systolic dimension; LVPWD, left ventricular posterior wall diastolic thickness; LVPWS, left ventricular posterior wall systolic thickness. Data are mean \pm SEM of 8 (7-day-old) or 5-6 (10-day-old) mice for each group. ${ }^{A} P<0.001,{ }^{B} P<0.01$ compared with WT.

$\mathrm{Ca}^{2+}$ by $50 \mathrm{nM}$ CaM and $1 \mu \mathrm{M}$ CaM. The extent of inhibition was comparable to that of WTRyR2 channels (not shown). Kinetic analysis showed no significant differences between CaM-depleted WT and mutant channels with regard to number of channel events and mean open and close times (Figure 6). Taken together, $\left[{ }^{3} \mathrm{H}\right]$ ryanodine binding and single-channel measurements suggest that substitution of 3 amino acid residues in RyR2 CaM regulatory domain reduces CaM inhibition in homozygous hearts without inducing major protein conformational changes. More-

$\left[{ }^{3} \mathrm{H}\right]$ ryanodine binding was measured with $R y r 2^{A D A / A D A}$ membranes in presence of high CaM concentration $(800 \mathrm{nM})$.

The effects of the ADA mutation on interaction between RyR2 and $\mathrm{CaM}$ were also examined in single-channel measurements. Membranes isolated from the hearts of WT (left panels) and homozygous (right panels) mice were fused with lipid bilayer. There was no significant difference in baseline $\left(0.1 \mu \mathrm{M}\right.$ cytoplasmic $\left.\mathrm{Ca}^{2+}\right)$ open-channel probability between WT and homozygous mutant channels (not shown). The regulatory effects of CaM, as reflected by changes in RyR channel open probabilities, were then determined in presence of 0.4 or $2 \mu \mathrm{M}$ free cis (cytosolic) $\mathrm{Ca}^{2+}$ by adding exogenous $\mathrm{CaM}$ to the cis (cytosolic) side of the bilayer. In good agreement with single-channel measurements of recombinant RyR2s (Supplemental Figure 2), addition of $1 \mu \mathrm{M}$ CaM inhibited both WT and homozygous mutant channels at $0.4 \mu \mathrm{M} \mathrm{Ca}^{2+}$, whereas $50 \mathrm{nM}$ CaM inhibited only WT channels significantly $(P<0.05$; Figure $6 \mathrm{~A})$. At $2 \mu \mathrm{M} \mathrm{Ca}^{2+}, 50 \mathrm{nM}$ and $1 \mu \mathrm{M}$ CaM did not affect activity of homozygous mutant channels, whereas the open probability of WT channels decreased to $56 \pm 4 \%$ and $51 \pm 7 \%$, respectively (Figure 6B). In reasonable agreement with $\left[{ }^{3} \mathrm{H}\right]$ ryanodine binding measurements (Figure $5 \mathrm{C}$ ), a majority RyR2 channels ( 9 of 10) from heterozygous hearts were inhibited at $2 \mu \mathrm{M}$ over, maintenance of CaM inhibition by the majority of heterozygous channels was consistent with our finding that Ryr $2^{+/ A D A}$ mice showed no major signs of cardiac hypertrophy.

$\mathrm{Ca}^{2+}$ transients in spontaneously beating cardiomyocytes isolated from bearts of WT and mutant mice. The functional effects of the RyR2ADA mutation were also probed by measuring $\mathrm{Ca}^{2+}$ transients in intact cultured cardiomyocytes, using fluo-4 and confocal laser scanning microscopy. We could distinguish between 2 types of spontaneously beating cardiomyocytes. In 1 group of cardiomyocytes, cytosolic $\mathrm{Ca}^{2+}$ concentration was rapidly increased, then maintained for varying times before declining to resting levels (Figure 7, A and B). Mean data showed that mean duration of elevated $\mathrm{Ca}^{2+}$ level was about 10 times greater in homozygous cardiomyocytes than in WT cardiomyocytes (bars in Figure 7, A, B, and D). In heterozygous cardiomyocytes, the plateau phase of the $\mathrm{Ca}^{2+}$ transient was also increased, but to a much smaller extent than in homozygous cardiomyocytes (Figure 7D). Differences were also observed in the time of $\mathrm{Ca}^{2+}$ removal. The time constant for decline to resting $\mathrm{Ca}^{2+}$ levels showed a significant increase in homozygous cardiomyocytes and a smaller (insignificant) increase in heterozygous myocytes as compared with WT myocytes (Figure 7E).
A

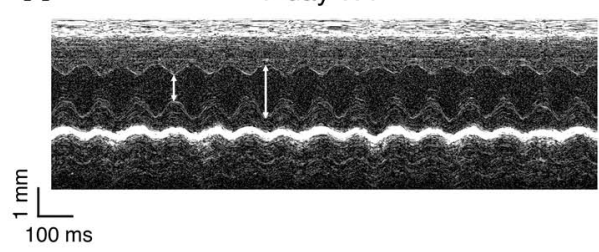

B 10-day WT 7-day WT

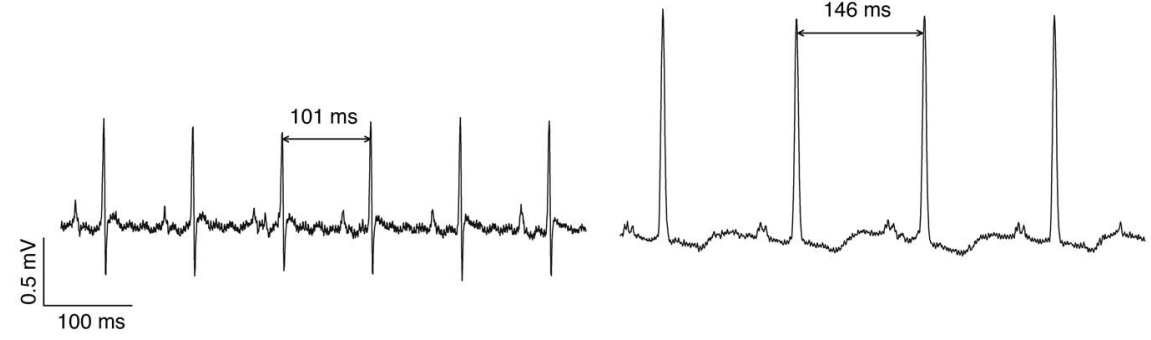

7-day HOM

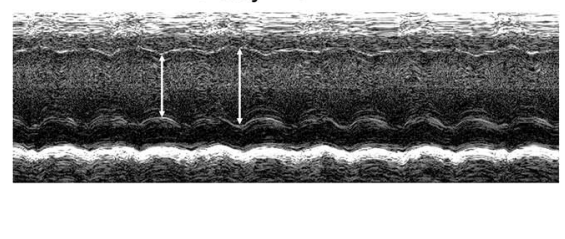

10-day HOM
Figure 4

Echocardiograms and electrocardiograms of WT and mutant mice. (A) Representative M-mode echocardiograms of 7-day-old $R y r 2^{+/+}$and Ryr2ADA/ADA mice. Left ventricular end-diastolic (right arrows) and end-systolic (left arrows) dimensions are indicated. (B) Representative electrocardiograms of 10-day-old WT and homozygous mice. 

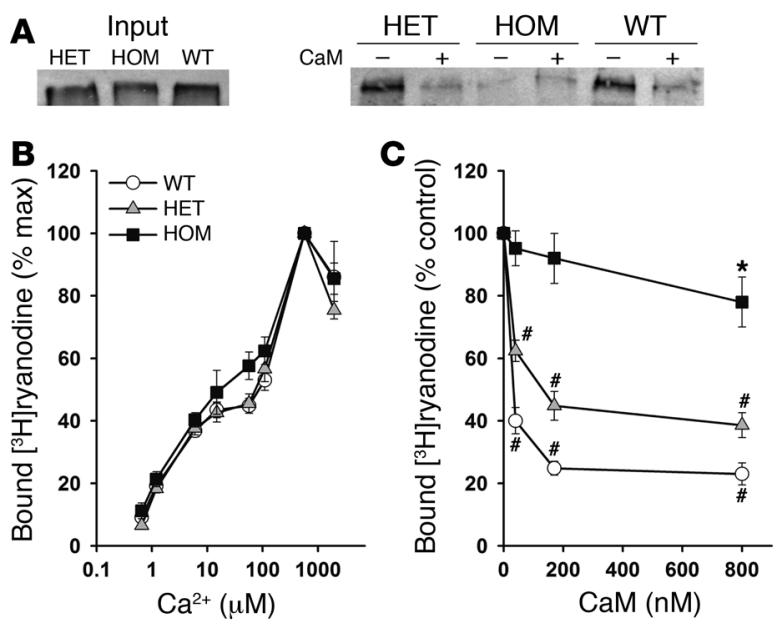

A second group of myocytes displayed repeated periods of incomplete $\mathrm{Ca}^{2+}$ removal and $\mathrm{Ca}^{2+}$ release before declining to the resting level (Figure 7C). This behavior was primarily observed in homozygous and heterozygous myocytes (13 of 27 and 8 of 23, respectively, versus 4 of 30 for WT). Mean data showed that the number of rapidly occurring, incomplete $\mathrm{Ca}^{2+}$ removal and $\mathrm{Ca}^{2+}$ release events was higher in homozygous cardiomyocytes $(10.5 \pm 2.2$ repeats, $n=13)$ than in heterozygous $(4.1 \pm 0.7, n=8)$ or WT $(2.0 \pm 0.0, n=4)$ cardiomyocytes. The duration of the plateau (Figure 7, A and B) and number of repetitive $\mathrm{Ca}^{2+}$ release events (Figure $7 \mathrm{C}$ ) were independent of culture days of cardiomyocytes.

Additional experiments with the 3 genotypes using the fluorescent $\mathrm{Ca}^{2+}$ indicator Fura- 2 showed no significant differences in the resting cytosolic $\mathrm{Ca}^{2+}$ levels of spontaneously beating cardiomyocytes (Figure 7F). Moreover, caffeine-induced $\mathrm{Ca}^{2+}$ release was not significantly different, as reflected by the ratio of peak minus baseline fluo-4 fluorescence to baseline fluorescence (Figure 7G), which suggested a similar SR $\mathrm{Ca}^{2+}$ content. Taken together, the data then suggest that an impaired CaM regulation of RyR2 alters cellular $\mathrm{SR} \mathrm{Ca}^{2+}$ release and cytosolic $\mathrm{Ca}^{2+}$ removal.

To determine whether the reduced rates of cytosolic $\mathrm{Ca}^{2+}$ removal in cardiomyocytes expressing the RyR2 $2^{\mathrm{ADA}}$ mutation are associated with decreased SERCA2a activity in intact hearts, we measured uptake rates by membrane fractions isolated from 1-, 7-, and 10-day hearts of the radioisotope ${ }^{45} \mathrm{Ca}^{2+}$. At day 1 and day 7 , a $25 \%-40 \%$ (not significant) decrease in the ${ }^{45} \mathrm{Ca}^{2+}$ uptake rates was measured in membrane fractions isolated from heterozygous and homozygous hearts as compared with hearts expressing WT-RyR2

\section{Figure 5}

CaM binding and regulation of RyR2 from hearts of WT and mutant mice. (A) Western blots of RyR2 bound to CaM-Sepharose beads. Input RyR2s (left) and RyR2s bound to CaM-Sepharose in the absence (-) or presence (+) of $2 \mu \mathrm{M} \mathrm{CaM}$ (right). (B and C) Specific $\left[{ }^{3} \mathrm{H}\right]$ ryanodine binding to crude membrane fractions from hearts of 7-day-old and 10-day-old WT, heterozygous, and homozygous mice was determined as described in Supplemental Methods. (B) $\mathrm{Ca}^{2+}$ dependence of $\left[{ }^{3} \mathrm{H}\right]$ ryanodine binding in absence of $\mathrm{CaM}$. (C) $\left[{ }^{3} \mathrm{H}\right]$ ryanodine binding as a function of $\mathrm{CaM}$ concentration at $1.2 \mu \mathrm{M} \mathrm{Ca}{ }^{2+}$. Data are the mean \pm SEM of $4-6$ experiments. ${ }^{*} P<0.05$, ${ }^{\sharp} P<0.01$ compared with control (no CaM added), as determined by Student's $t$ test.
(Table 2). At day 10, the ${ }^{45} \mathrm{Ca}^{2+}$ uptake rates of membranes isolated from homozygous hearts were significantly lower than those from WT hearts $(12.3 \pm 1.6$ versus $4.9 \pm 1.4 \mathrm{nmol} / \mathrm{mg}$ protein $/ \mathrm{min}$; Table 2 ). We conclude that, in the hearts of 10-day-old mice, the RyR2ADA mutation is associated with reduced SERCA2a activity and thereby may contribute to reduced rate of cytosolic $\mathrm{Ca}^{2+}$ sequestration in cultured mutant cardiomyocytes.

Activities of signaling molecules and CaM concentrations in WT and mutant hearts. We examined whether lack of CaM binding to RyR2 $2^{\mathrm{ADA}}$ increased the pool of CaM available for binding to CaM-dependent kinases and phosphatases, leading to their activation in homozygous mice. However, no increase in CaMKII activity $(99 \pm 12 \%[n=3]$ of WT activity) was observed in 1-day-old homozygous mice, which already showed a hypertrophic response. Furthermore, amounts of CaM maximally bound to RyR2 (1.5-2.0 $\mathrm{pmol} / \mathrm{mg}$ protein, or $0.3-0.4 \mu \mathrm{M}$ CaM) represent only a small fraction of total CaM. Total CaM concentration in hearts of WT $(9.1 \pm 0.6 \mu \mathrm{M})$ were slightly (but not significantly) higher than in heterozygous $(7.4 \pm 1.1 \mu \mathrm{M})$ and homozygous $(8.2 \pm 0.7 \mu \mathrm{M})$ 10-day-old mice $(n=4)$, as determined by quantitative immunoblot analysis.

We also considered the possibility that impaired CaM regulation of RyR2 is associated with an aberrant activity of signaling molecules implicated in cardiac hypertrophy. In pathological cardiac hypertrophy, phosphorylation of class II histone deacetylases (HDACs) by CaMKII, protein kinases C and D, and other yet to be identified kinases results in derepression of myocyte enhancer factor-2 (MEF2) and other transcription factors $(18,19)$. We used GST-HDAC4 fusion proteins (amino acids 419-670) to test for an

\section{Table 2}

Biochemical properties of WT and mutant hearts

\begin{tabular}{|c|c|c|c|c|c|c|}
\hline \multirow[b]{2}{*}{ Age (d) } & \multicolumn{3}{|c|}{$\mathrm{B}_{\max }$ of $\left[{ }^{3} \mathrm{H}\right]$ ryanodine binding (pmol/mg protein) } & \multicolumn{3}{|c|}{${ }^{45} \mathrm{Ca}^{2+}$ uptake (nmol/mg protein/min) } \\
\hline & WT & HET & HOM & WT & HET & HOM \\
\hline 1 & $0.41 \pm 0.08(5)$ & $0.38 \pm 0.05(8)$ & $0.31 \pm 0.08(5)$ & $8.0 \pm 2.0(3)$ & $5.9 \pm 0.6(7)$ & $6.0 \pm 0.6(4)$ \\
\hline 7 & $0.48 \pm 0.07(13)$ & $0.40 \pm 0.05(16)$ & $0.19 \pm 0.04(11)^{A}$ & $10.2 \pm 2.1(6)$ & $7.5 \pm 1.9(6)$ & $6.2 \pm 1.1(6)$ \\
\hline 10 & $0.43 \pm 0.04(12)$ & $0.32 \pm 0.04(17)^{\mathrm{B}}$ & $0.13 \pm 0.02(15)^{C}$ & $12.3 \pm 1.6(5)$ & $11.9 \pm 1.2(6)$ & $4.9 \pm 1.4(5)^{\mathrm{A}}$ \\
\hline 91 & $0.90 \pm 0.06(4)$ & $0.78 \pm 0.03(4)$ & - & $12.8 \pm 0.8(4)$ & $13.7 \pm 2.2(4)$ & - \\
\hline
\end{tabular}


A
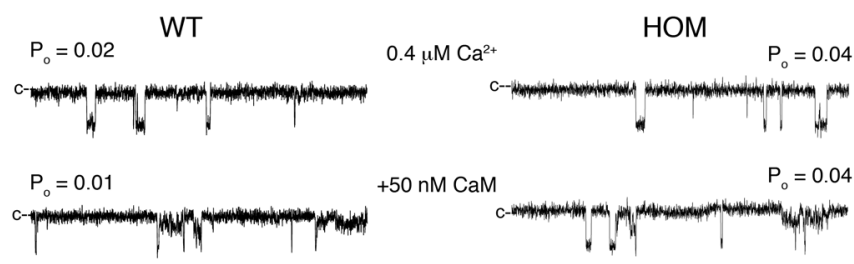

$+50 \mathrm{nM} \mathrm{CaM}$

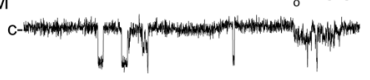

$$
P_{0}=0.01
$$
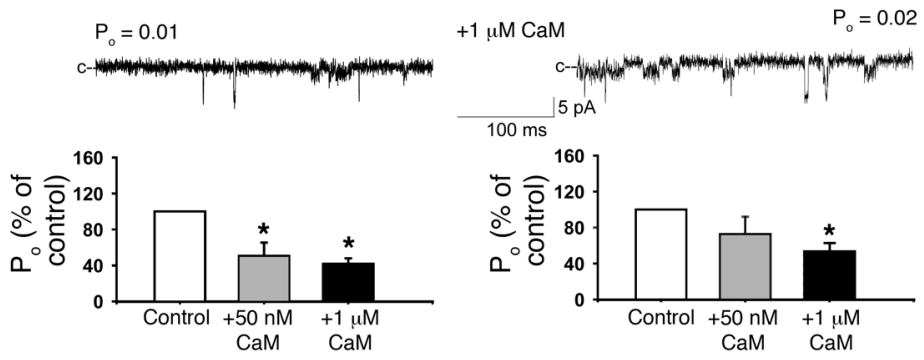

B WT
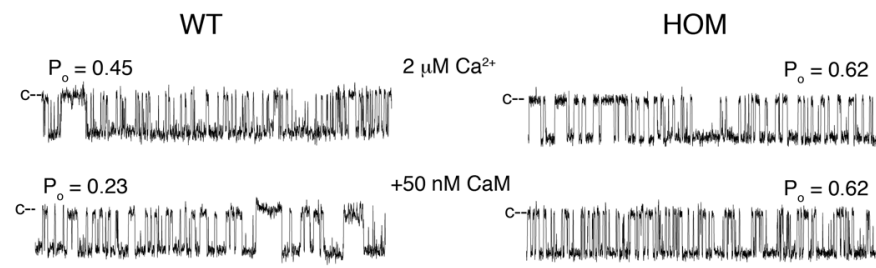

+50 nM CaM
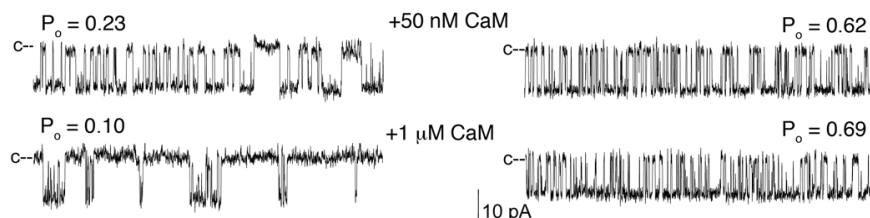

$+1 \mu \mathrm{M} \mathrm{CaM}$
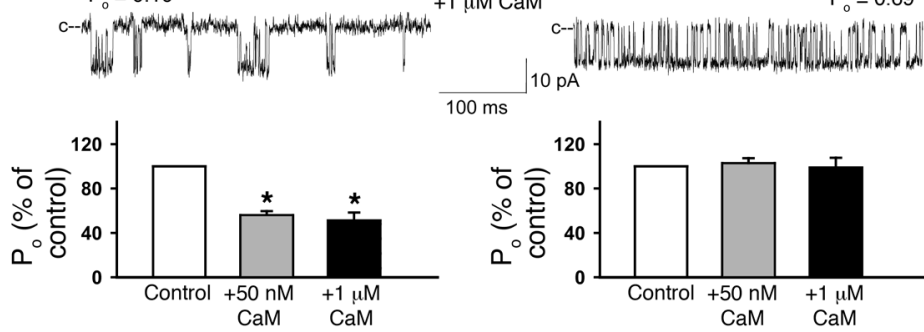

$100 \mathrm{~ms}$ $10 \mathrm{pA}$

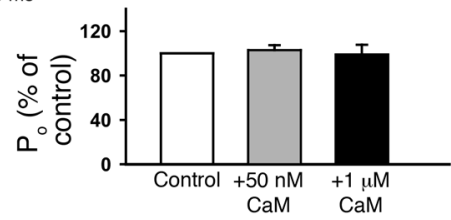

\section{Figure 6}

Effects of CaM on single WT and homozygous mutant singlechannel activities. Membranes isolated from hearts of 7 - to 10-day-old $R y r 2^{+/+}$and Ryr2ADA/ADA mice were fused with lipid bilayer. Single-channel currents (downward deflections from closed levels [c--]) were recorded at $-20 \mathrm{mV}$ in the presence of $0.4 \mu \mathrm{M}(\mathbf{A})$ and $2 \mu \mathrm{M}(\mathbf{B})$ cis (cytosolic) $\mathrm{Ca}^{2+}$ as described in Supplemental Methods in the absence of CaM (top traces) and following the addition of $50 \mathrm{nM}$ (middle traces) and $1 \mu \mathrm{M}$ (bottom traces) cis CaM. Bottom panels show mean openchannel probabilities \pm SEM of 4-7 channel recordings, normalized to control. ${ }^{*} P<0.05$ compared with control (no CaM added), determined using Student's $t$ test. Mean channel parameters at $2 \mu \mathrm{M}$ cis (cytosolic) $\mathrm{Ca}^{2+}$ in absence of $\mathrm{CaM}$ (control) were as follows for WT and mutant channels, respectively: open-channel probability $\left(\mathrm{P}_{\mathrm{o}}\right), 0.45 \pm 0.06$ and $0.35 \pm 0.14$; events per minute, $4909 \pm 1997$ and $8721 \pm 3797$; mean open time $\left(T_{0}\right), 7.3 \pm 2.5$ and $3.4 \pm 1.6 \mathrm{~ms}$; mean close time $\left(T_{c}\right), 14.9 \pm 6.2$ and $11.3 \pm 7.3 \mathrm{~ms}$. Channel parameters were calculated from 3 and 4 recordings, respectively, that contained only single-channel activity.

Because traditional enzyme assays are technically and theoretically difficult (21), we tested for an enhanced calcineurin activity in the hearts of homozygous mice by determining the mRNA levels of myocyte-enriched calcineurin-interacting protein 1 (MCIP1) by quantitative RT-PCR. As part of a compensatory response to an increased calcineurin activity, the protein levels of MCIP1 are upregulated in hypertrophic hearts (22). We found that the mRNA level of MCIP1 was significantly increased in homozygous hearts at day 7 $(148 \pm 15 \% ; n=10)$ and day $10(201 \pm 25 \% ; n=19)$, but not at day $1(79 \pm 7 \% ; n=10)$ compared with WT. It is therefore likely that the calcineurin/NFAT signaling pathway also has a role in gene remodeling in homozygous hearts. upregulation of kinases implicated in class II HDAC phosphorylation and gene remodeling. A significantly increased phosphorylation of HDAC4 by lysates from homozygous hearts at day 1 as compared with WT hearts was observed (Figure 8, A and B). R601F mutant HDAC4, which lacks CaMKII docking site (19), was also phosphorylated to a greater extent by lysates from homozygous hearts than by lysates from WT hearts. In complementary studies, autocamtide- 2 related inhibitory peptide, a specific inhibitor of CaMKII, did not substantially reduce HDAC phosphorylation (data not shown). By comparison, phosphorylation of HDAC4 was reduced to background levels by the nonspecific kinase inhibitor staurosporin. The results are consistent with our finding that heart homogenates of 1-day-old WT and homozygous mice had comparable CaMKII activities and suggest that kinase(s) other than CaMKII enhanced HDAC4 phosphorylation. In agreement with increased phosphorylation of HDAC4, MEF2 activities were upregulated in nuclear fractions from homozygous hearts (Figure 8C), which suggests a derepression of class II HDAC target genes that contribute to cardiac hypertrophy and early death of the homozygous mutant $\left(R y r 2^{A D A / A D A}\right)$ mice.

We also tested the possibility that an aberrant $\mathrm{SR} \mathrm{Ca}^{2+}$ release increased the activity of calcineurin, a $\mathrm{Ca}^{2+} / \mathrm{CaM}$-activated serine/ threonine phosphatase that through dephosphorylation of nuclear factor of activated T cell (NFAT) transcriptionally regulates signaling pathways implicated in pathological cardiac hypertrophy (20).

\section{Discussion}

$\mathrm{Ca}^{2+}$ and CaM play a crucial role in cardiac excitation-contraction coupling. Ample evidence has been provided that the entry of activator $\mathrm{Ca}^{2+}$ through the L-type $\mathrm{Ca}^{2+}$ channel is regulated by CaM and CaMKII, which may thereby regulate $\mathrm{SR} \mathrm{Ca}^{2+}$ release $(4,23$, 24). It has also been shown that RyR 2 is inhibited by CaM in vitro (25) and phosphorylated by CaMKII $(5,26,27)$. The physiological importance of a direct interaction between RyR2 and CaM in cardiac muscle, however, has remained unclear. Herein we describe a genetically modified mouse that has mutations in the CaM-binding domain of RyR2. The high specificity of our approach enabled us to specifically ascribe the functional changes to only 1 of the multiple roles of CaM in cardiac excitation-contraction coupling. The results show that impaired regulation of the RyR2 ion channel by CaM is associated with cardiac hypertrophy, which led to the early death of the homozygous mutant mice. However, we were unable to determine the exact cause of death because due to the age of mice it was not possible to continuously monitor electrocardiograms.

Cardiac hypertrophy is a complex process involving multiple signaling pathways $(20,28)$. The results of our studies add to a growing body of work indicating that an aberrant SR $\mathrm{Ca}^{2+}$ release is one of the mechanisms leading to cardiac hypertrophy and heart failure. Other studies have shown that protein kinase A-mediated hyperphosphorylation of the cardiac RyR contributes to impaired SR and contractile function during heart failure (5). Overexpression 

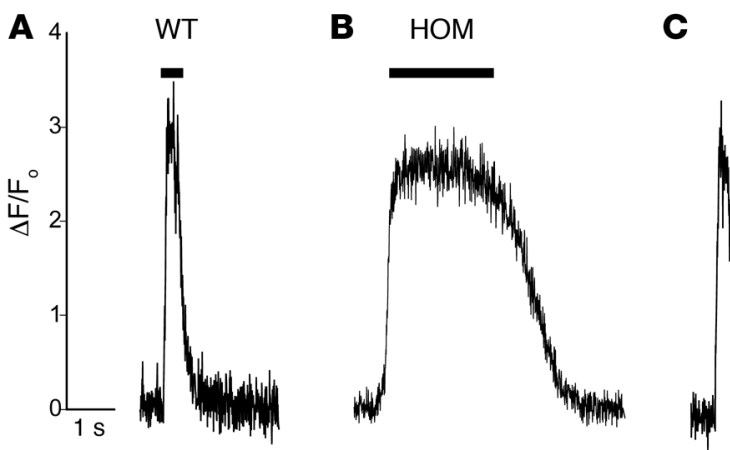

HOM
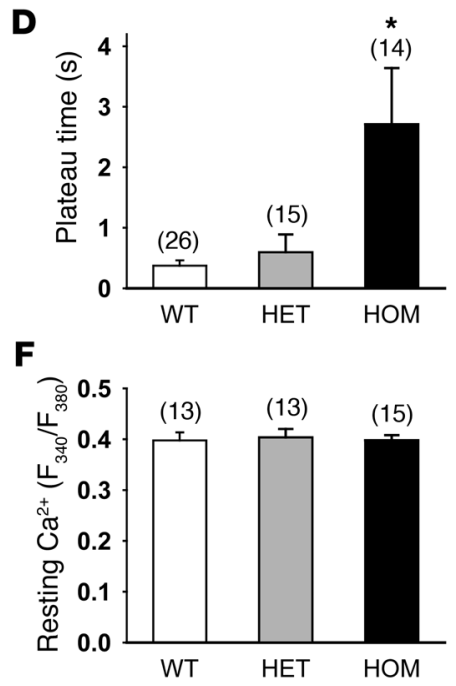

E

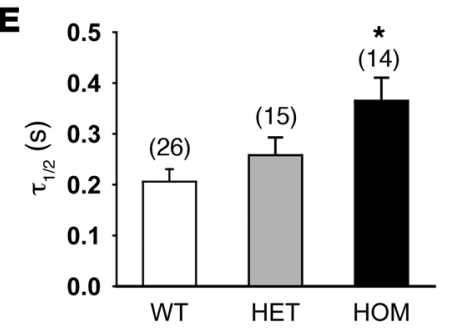

G

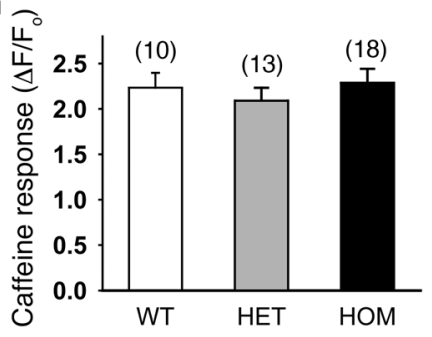

Figure 7

$\mathrm{Ca}^{2+}$ imaging of cardiomyocytes from WT and mutant hearts. (A-C) $\mathrm{Ca}^{2+}$ transients in cultured neonatal cardiomyocytes were measured with $\mathrm{Ca}^{2+}$ indicator dye fluo- 4 and confocal line scanning microscopy as described in Methods. Representative traces of $\mathrm{Ca}^{2+}$ transients in WT and homozygous cardiomyocytes are shown. Bars indicate sustained time of peak areas for $\mathrm{Ca}^{2+}$ transients. (D) Sustained time of peak values of $\mathrm{Ca}^{2+}$ transients of cardiomyocytes (Bars in $\mathbf{A}$ and $\mathbf{B})$. (E) Half-maximal times $\left(\tau_{1 / 2}\right)$ of $\mathrm{Ca}^{2+}$ removal by cardiomyocytes that showed only $1 \mathrm{Ca}^{2+}$ release event before declining to $\mathrm{Ca}^{2+}$ resting level. (F) Resting $\mathrm{Ca}^{2+}$ levels were measured with Fura-2 using 340-nm and 380-nm excitation wavelengths. Ratio of $F_{340}$ to $F_{380}$ is shown. (G) SR Ca ${ }^{2+}$ release induced by addition of $6.3 \mathrm{mM}$ caffeine was measured using fluo- $4 . \Delta F / F_{0}$, difference in peak and baeline fluorescence divided by baseline fluorescence. Data are the mean \pm SEM of number of experiments shown in parentheses over each bar. ${ }^{*} P<0.01$ compared with WT.

free and $\mathrm{Ca}^{2+}$-bound forms of CaM (10). In the present study, we attenuated the regulation of RyR2 by CaM by preparing gene-targeted mice with 3 amino acid substitutions (RyR2 ${ }^{\mathrm{ADA}}$ ) in the CaM-binding domain. We characterized the RyR2 mutant channels in $\left[{ }^{3} \mathrm{H}\right]$ ryanodine binding and single-channel measurements and found that homozygous expression of RyR2 ${ }^{\mathrm{ADA}}$ greatly reduced the efficacy of CaM inhibition of RyR2. In contrast, CaM inhibition of $\left[{ }^{3} \mathrm{H}\right]$ ryanodine binding was maintained in membranes isolated from heterozygous mice. These data are in agreement with our finding that homozygous but not heterozygous mice exhibited a severe form of cardiac hypertrophy. Heterozygous mice predomi-

of the SR lumenal $\mathrm{Ca}^{2+}$ binding protein calsequestrin in cardiomyocytes increased SR Ca ${ }^{2+}$ levels, impaired SR $\mathrm{Ca}^{2+}$ release, and was associated with cardiac myopathy (29-31). Constitutively elevated levels of CaM (32) and CaMKII (33) in the hearts of mutant mice resulted in cardiac hypertrophy, presumably by affecting multiple mechanisms including SR $\mathrm{Ca}^{2+}$ release and sequestration. We found that class II HDAC/MEF2 signaling was enhanced in homozygous hearts at day 1 , and we considered the possibility that an altered SR $\mathrm{Ca}^{2+}$ release increased CaMKII activity and HDAC phosphorylation in 1-day-old homozygous mice, which already showed a hypertrophic response. However, our data suggest that other kinases that have yet to be identified have a major role in upregulating HDAC4/MEF2 signaling in Ryr2 $2^{A D A / A D A}$ mice. Calcineurin is another $\mathrm{Ca}^{2+}$-dependent signaling molecule implicated in cardiac hypertrophy (20, 28). Increased mRNA levels of MCIP1 at days 7 and 10 suggest that calcineurin signaling pathway is also involved in cardiac hypertrophy of homozygous mice. However, we observed no change in MCIP1 expression at day 1 , which suggests that changes in calcineurin signaling may be secondary to those in HDAC/MEF2 signaling. A more detailed determination of the role of calcineurin is currently underway in which we cross-breed our mutant mice with calcineurin-deficient mice.

RyR2 has a single CaM-binding domain (amino acid residues 3583-3603) that is shared by $\mathrm{Ca}^{2+}$
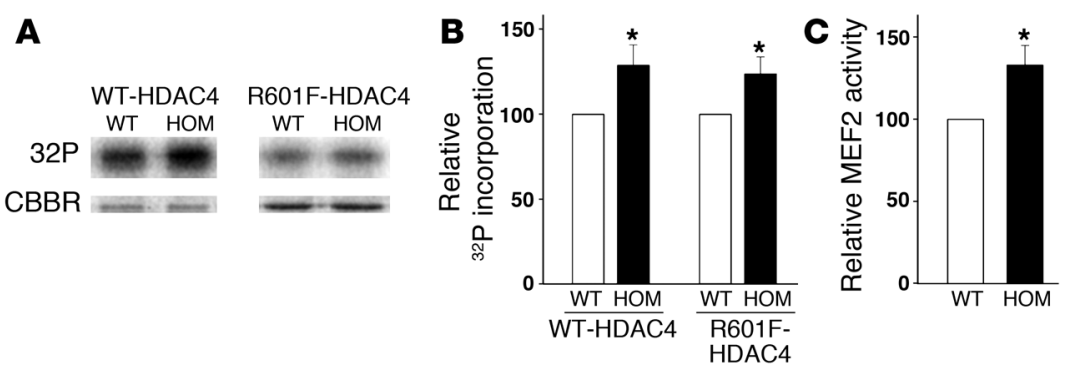

Figure 8

Activities of HDAC kinase and MEF2 in WT and homozygous hearts. (A and B) GSTHDAC4 fusion proteins were used as a substrate to measure kinase activities of lysates from 1-day hearts. (A) $\left.{ }^{32} \mathrm{P}\right]$ incorporation (top) and Coomassie brilliant blue staining (CBBR; bottom) of GST-HDAC4 or GST-HDAC4 with R601F mutation. (B) [ ${ }^{32} \mathrm{P}$ ] radioactivity in GST-HDAC4 SDS-PAGE gel bands was quantified by liquid scintillation counting. (C) MEF2 activities of nuclear fractions from 1-day WT and homozygous hearts. Data are mean \pm SEM of $5-6$ experiments. ${ }^{*} P<0.05$ compared with WT. 
genes associated with cardiac hypertrophy. Moreover, 13-week-old heterozygous mice had heart weight to body weight ratios identical to those of WT mice. Thus, a small fraction of homotetrameric mutant RyR2 channels impaired in their regulation by CaM, if present in heterozygous mice (see above), was not sufficient to lead to the development of cardiac hypertrophy. On the other hand, an impaired CaM regulation of RyR2 caused severe cardiac hypertrophy and early death of the homozygous mutant mice. In support of the hypothesis of an early hypertrophic response, we observed an increased heart weight to body weight ratio and upregulation of genes associated with cardiac hypertrophy in mice as early as 1 day after birth. Greater differences in these parameters were observed in 7- and 10-day-old mice. Biochemical analysis of membrane fractions indicated a moderately (but not significantly) decreased RyR2 level and reduced SR $\mathrm{Ca}^{2+}$ uptake activity in hearts of 1-day-old mice and more pronounced $(P<0.01)$ reduction in SR function in hearts of 7-day-old (RyR2 level) and 10-day-old mice (RyR2 level and SR Ca ${ }^{2+}$ uptake activity). Echocardiography and electrocardiography extended these data to intact hearts. Heart rates of homozygous mice were significantly slower than those of WT mice in both measurements. Echocardiography showed a greatly decreased cardiac function in 7- and 10-day homozygous hearts as compared with WT hearts.

During an action potential, $\mathrm{Ca}^{2+}$ entering the cell via the L-type $\mathrm{Ca}^{2+}$ channel triggers the release of large amounts of $\mathrm{Ca}^{2+}$ from the $\mathrm{SR}$ by opening $\mathrm{Ca}^{2+}$-gated RyR2 channels. However, the termination of release of $\mathrm{Ca}^{2+}$ from the SR has remained one of the least understood steps in cardiac excitation-contraction coupling. While a number of mechanisms have been proposed, none has been fully accepted (35). Mechanisms proposed include time-dependent $\mathrm{Ca}^{2+}$-induced inactivation of RyR2 (36), depletion of SR Ca ${ }^{2+}(37)$, and the simultaneous closing of all active RyRs in a release unit to reduce the $\mathrm{Ca}^{2+}$ concentration to a subthreshold activation level (38, 39). Previously, we suggested that CaM may have a role in the termination of $\mathrm{SR} \mathrm{Ca}^{2+}$ release, based on our observation that, at $\mathrm{Ca}^{2+}$ concentrations of less than $10 \mu \mathrm{M}, \mathrm{CaM}$ increased the duration of the close times of single RyR2 channels incorporated into an artificial bilayer (11). Longer channel closings allow $\mathrm{Ca}^{2+}$ more time to diffuse away from the release sites, thereby reducing the probability of channel reopening. The present results, demonstrating that an impaired CaM regulation of RyR2 results in sustained $\mathrm{Ca}^{2+}$ transients in cardiomyocytes isolated from homozygous mice supports this idea. An intriguing finding was that heterozygous and homozygous cardiomyocytes often exhibited repeated periods of incomplete $\mathrm{Ca}^{2+}$ uptake followed by another $\mathrm{Ca}^{2+}$ release episode before declining to the resting level. Evidently, RyR2 channels reopened before $\mathrm{Ca}^{2+}$ concentrations declined sufficiently to eliminate channel reopening. Possible explanations include decreased SERCA2a activity and/or repeated membrane depolarization, resulting in the repetitive activation of $\mathrm{L}$-type $\mathrm{Ca}^{2+}$ and $\mathrm{RyR} 2$ channels. Changes

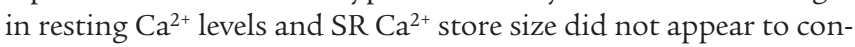
tribute to abnormal $\mathrm{Ca}^{2+}$ release in $R y r 2^{A D A} / A D A$ cardiomyocytes, as both were not significantly different between the 3 groups of cardiomyocytes. We caution, however, that due to the early death of the homozygous mutant mice these studies were done with cardiomyocytes isolated from the hearts of 1-day-old mice. Their culture for $7-13$ days might have resulted in gene regulation different from that found in intact hearts. $\mathrm{Ca}^{2+}$ transients in the hearts of 7 - to 10-day-old homozygous mice are most likely less severely altered than in isolated cardiomyocytes and remain to be determined.
Several mutations of RyR2 in humans have been reported to cause catecholaminergic polymorphic ventricular tachycardia (CPVT) and arrhythmogenic right ventricular cardiomyopathy (40). A deficiency in SR lumenal cardiac calsequestrin in humans (41) and mice (42) as well as a missense mutation (D307H) (43) also caused CPVT. These mutations result in imbalance of $\mathrm{Ca}^{2+}$ handling $(40,42,44)$. Although an impaired regulation of RyR2 by CaM has not been demonstrated in human cardiomyopathies, our genetically modified mice provide a promising model that should be helpful to investigators studying cardiac hypertrophy and heart failure in humans.

\section{Methods}

Materials. $\left[{ }^{3} \mathrm{H}\right]$ ryanodine was obtained from PerkinElmer, Tran ${ }^{35} \mathrm{~S}$-label from ICN Radiochemicals, unlabeled ryanodine from EMD Biosciences, Complete protease inhibitors from Roche Applied Science, and phospholipids from Avanti Polar Lipids Inc. Unlabeled CaM and $\left[{ }^{35} \mathrm{~S}\right] \mathrm{CaM}$ were prepared as previously described (34). Unless otherwise specified, all other chemicals were obtained from Sigma-Aldrich.

Generation of mice with mutations in CaM-binding domain of RyR2. Ryr2 gene was cloned from 129/SvEv mouse genomic DNA library. Multiple base changes in exon 75, which encodes the CaM-binding domain, were introduced by pfu polymerase-based chain reaction using mutagenic oligonucleotides and the QuikChange site-directed mutagenesis kit (Stratagene). A 6.5-kbp fragment with the ADA mutation and a 1.2-kbp fragment were cloned into pBR322 (New England Biolabs) containing neomycin-resistant gene flanked by loxP sequences and thymidine kinase gene (Supplemental Figure 3). Mutant mice carrying the ADA mutation were prepared as described in Supplemental Methods.

The mice were handled following the NIH guidelines for the use and care of experimental animals. All experiments were approved by the Institutional Animal Care and Use Committee of the University of North Carolina at Chapel Hill.

Morphological analysis. Mouse hearts at 10 days of age were fixed with $4 \%$ (w/v) paraformaldehyde in PBS ( $\mathrm{pH} 7.4)$ and dehydrated by increasing concentrations of ethanol in water. Paraffin sections ( $5 \mu \mathrm{m}$ in thickness) of tissues were cut and stained with $\mathrm{H} \& \mathrm{E}$ and Masson trichrome. To visualize cell membranes of cross-sectioned cardiomyocytes, paraffin-free heart sections were incubated with $50 \mu \mathrm{g} / \mathrm{ml}$ TRITC-conjugated wheat germ agglutinin in PBS for 1 hour and then washed 3 times with PBS. TRITC fluorescence images were captured and cell cross-sectional areas were calculated using ImageJ software (version 1.34s; http://rsb.info.nih.gov/ij/).

Quantitative RT-PCR. Gene expression was measured by quantitative RTPCR using the ABI Prism 7700 Sequence Detector (Applied Biosystems). RNA was isolated from left and right ventricles of 1-day-old mice and left ventricle of 7- and 10-day-old mice with the ABI Prism 6700 Automated Nucleic Acid Workstation according to the manufacturer's protocol. Primers and the corresponding fluorogenic probes for $\beta$-myosin heavy chain, atrial natriuretic peptide, brain natriuretic peptide, and $\beta$-actin genes were as previously described (45). Forward and reverse primers for RyR2 were 5'-CTGTCCCTGAGGTACAAGAA-3' and 5'-AGCTTTCTCTGGTTCCGACT-3', respectively. Fluorogenic probe was FaM-5'-TTCAGGGAGCAGAAGGCGAAAGAGGA-3'-TAMRA. Forward and reverse primers and probe for MCIP1 were 5'-CCCCGTCATAAATTACGATCT-3', 5'-ACACTGGGAGTGGTGTCTGT-3', and 5'-FaM-AGTTCATACTTCTCTCCTGGCCCCA-TAMRA-3', respectively. Relative levels of gene expression as a percentage of WT were determined for each gene with $\beta$-actin as reference.

Echocardiography and electrocardiography. To determine left ventricular cardiac function, transthoracic M-mode echocardiography was performed on restrained and unanesthetized 7- and 10-day-old mice using Vevo 660 high-resolution imaging system (VisualSonics). Electrocardio- 
grams were performed on restrained, unanesthetized 10-day-old mice using mouse pad with 4 electrodes connected to electronic control module (THM100; Indus Instruments).

Preparation of membrane fractions. Hearts were homogenized in $20 \mathrm{mM}$ imidazole, $\mathrm{pH}$ 7.0, $0.3 \mathrm{M}$ sucrose, $150 \mathrm{mM} \mathrm{NaCl}, 0.1 \mathrm{mM}$ EGTA, and protease inhibitors (Complete; Roche Applied Science; $1 \mathrm{mM}$ glutathione, oxidized form) with a Tekmar Tissumizer for twice for 5 seconds each time at a setting of $13,500 \mathrm{rpm}$. Homogenates were centrifuged for 45 minutes at 100,000 $\mathrm{g}$ in a Type $75 \mathrm{Ti}$ rotor (Beckman), and pellets were resuspended in the above buffer without EGTA and glutathione to obtain a crude membrane fraction. Membranes were stored in small aliquots at $-135^{\circ} \mathrm{C}$.

Single-channel analysis. Single-channel measurements of WT and mutant RyR2s were performed in planar lipid bilayers as described in ref. 46 and Supplemental Methods.

$\left[{ }^{3} \mathrm{H}\right]$ ryanodine binding. Ryanodine binds with high specificity to RyRs and is widely used as a probe of channel activity because of its preferential binding to the open-channel state $(15) .\left[{ }^{3} \mathrm{H}\right]$ ryanodine binding experiments were performed with crude membrane fractions from hearts, as described in Supplemental Methods.

CaM-Sepharose pull-down assay. Membrane fractions of mouse hearts were solubilized in $40 \mathrm{mM}$ NaPIPES, pH 7.4, $1 \mathrm{M} \mathrm{NaCl}, 5 \mathrm{mM}$ DTT, $0.1 \mathrm{mM}$ EGTA, 2.5\% Triton X-100, and protease inhibitors. After eliminating the insoluble fractions by centrifuge, supernatant was diluted with 7 volumes of $\mathrm{H}_{2} \mathrm{O}$ and then incubated with CaM-Sepharose (GE HealthCare) for 20 hours at $4^{\circ} \mathrm{C}$ in the presence of $900 \mu \mathrm{M} \mathrm{Ca}^{2+}$. After washing the CaM-Sepharose, bound RyR2s were eluted and analyzed by Western blot.

${ }^{45} \mathrm{Ca}^{2+}$ uptake. ATP-dependent ${ }^{45} \mathrm{Ca}^{2+}$ uptake by crude membrane fractions was determined using a filtration method. ${ }^{45} \mathrm{Ca}^{2+}$ uptake was initiated by placing membranes in $0.15 \mathrm{M} \mathrm{KCl} ; 20 \mathrm{mM}$ imidazole, $\mathrm{pH}$ 7.0; solution containing $5 \mathrm{mM}$ ATP, $8 \mathrm{mM} \mathrm{Mg}^{2+}$, and $5 \mathrm{mM}$ potassium oxalate $\left(\mathrm{a} \mathrm{Ca}^{2+}\right.$ precipitating agent to increase $\mathrm{Ca}^{2+}$ uptake capacity; ref. 47); $10 \mu \mathrm{M}$ ruthenium red (to inhibit RyRs; ref. 48); $5 \mathrm{mM} \mathrm{NaN}_{3}$ (to inhibit mitochondrial $\mathrm{Ca}^{2+}$ uptake); 1 mM EGTA; and $\mathrm{Ca}^{2+}$ and ${ }^{45} \mathrm{Ca}^{2+}$ to yield a free $\mathrm{Ca}^{2+}$ concentration of $0.5 \mu \mathrm{M}$. To obtain ${ }^{45} \mathrm{Ca}^{2+}$ uptake rates, aliquots were placed at 2.5 , 5 , and 10 minutes on $0.45 \mu \mathrm{M}$ Millipore filters under vacuum and rinsed with three 3 -ml volumes of ice-cold $\left({ }^{\circ} 0\right)$ solution containing $0.175 \mathrm{M} \mathrm{KCl}$, $5 \mathrm{mM}$ imidazole, $\mathrm{pH}$ 7.0. Radioactivity remaining with the vesicles on the filters was determined by liquid scintillation counting.

Intracellular $\mathrm{Ca}^{2+}$ imaging. Neonatal cardiomyocytes were prepared from the ventricular muscle of mice approximately 1 day old using Neonatal Cardiomyocyte Isolation System (Worthington Biochemical Corp.) according to the manufacturer's protocol. Cells were maintained for 7-13 days in M199 medium with $10 \%$ fetal bovine serum at $37^{\circ} \mathrm{C}$ with $5 \% \mathrm{CO}_{2}$. Intracellular $\mathrm{Ca}^{2+}$ transients were recorded using fluorescent $\mathrm{Ca}^{2+}$ indicator dye fluo-4, AM, (Invitrogen) and confocal laser scanning microscopy (Zeiss LSM 510). Cells were incubated with $5 \mu \mathrm{M}$ fluo-4, AM, in culture media at $37^{\circ} \mathrm{C}$ with $5 \% \mathrm{CO}_{2}$. After loading for 30 minutes, cells were rinsed with L15 media containing 10\% fetal bovine serum and 15 mM NaHEPES, $\mathrm{pH}$ 7.3, to remove nonhydrolyzed fluorophore. Spontaneously beating cells were defined as regions of interest, and fluorescence changes of line image excited by $488-\mathrm{nm}$ argon laser as a function of time were measured through 505-nm long-pass filter at room temperature.

Resting $\mathrm{Ca}^{2+}$ levels of cardiomyocytes were monitored with Fura-2 and inverted microscope (Nikon TE2000-U) with high-sensitivity charge-coupled device camera (DVC1412; Digital Video Camera Co.). Cardiomyocytes were loaded with $5 \mu \mathrm{M}$ Fura-2 (AM) (TEF Labs) as described above and excited alternatively at $340 \mathrm{~nm}$ and $380 \mathrm{~nm}$. The fluorescence emissions of spontaneous beating cells were collected through 470-550 $\mathrm{nm}$ band-pass filter. To compare the resting $\mathrm{Ca}^{2+}$ level of experimental groups, the ratio of emission signals at $340 \mathrm{~nm}$ and $380 \mathrm{~nm}$ excitation was calculated.

Caffeine-induced $\mathrm{Ca}^{2+}$ release was measured with fluo- 4 and the inverted microscope system. Fluorescence changes of cytoplasm in response to addition of $6.3 \mathrm{mM}$ caffeine were collected through 515- to 555-nm band-pass filter. Excitation wavelength range was from $483 \mathrm{~nm}$ to $495 \mathrm{~nm}$.

Measurement of CaMKII, HDAC kinases, and MEF2. CaMKII activities were measured using SignaTECT Calcium/Calmodulin-dependent Protein Kinase Assay System (Promega). Briefly, hearts were homogenized in 20 mM Tris-HCl, pH 8.0, 2 mM EGTA and 2 mM EDTA, 2 mM DTT, protease inhibitors (Complete; Roche Applied Science) and phosphatase inhibitors (Sigma-Aldrich) with a Tekmar Tissumizer twice for 5 seconds each time at a setting of 13,500 rpm. Homogenates were centrifuged for 10 minutes at $350 \mathrm{~g}$ to obtain a supernatant fraction that was assayed for CaMKII activity according to the manufacturer's instructions.

HDAC kinase activities were determined as previously described (19). Briefly, heart lysates (prepared in $20 \mathrm{mM}$ Tris [pH 7.4], $150 \mathrm{mM} \mathrm{NaCl}, 0.6 \%$ NP-40, and protease inhibitors) were incubated with glutathione-S-transferase-HDAC4 fusion proteins (amino acids 419-670) for 4 hours at $4^{\circ} \mathrm{C}$. After washing with lysis buffer, beads were resuspended in kinase reaction buffer (25 mM HEPES [pH 7.6], $10 \mathrm{mM} \mathrm{MgCl}, 0.1 \mathrm{mM} \mathrm{CaCl}_{2}, 12.5 \mu \mathrm{M}$ $\mathrm{ATP}$, and $\left.5 \mu \mathrm{Ci}\left[\gamma_{-}{ }^{32} \mathrm{P}\right] \mathrm{ATP}\right)$, and reactions were performed for 30 minutes at room temperature. Proteins were resolved in SDS-PAGE, and [ $\left.{ }^{32} \mathrm{P}\right]$ radioactivity was analyzed by phosphoimager and liquid scintillation counting.

MEF2 activation was measured using Active Motif TransAM MEF2 kit according to the manufacturer's instructions.

Biochemical assays and data analyses. Western blot analysis and a standard curve prepared with purified CaM were used to determine total CaM concentrations in the hearts of the 3 genotypes. Free $\mathrm{Ca}^{2+}$ concentrations were obtained by including in solutions the appropriate amounts of $\mathrm{Ca}^{2+}$ and EGTA as determined using the stability constants and the computing method described in ref. 49 . Free $\mathrm{Ca}^{2+}$ concentrations of $1 \mu \mathrm{M}$ or more were verified with the use of a $\mathrm{Ca}^{2+}$ selective electrode.

Results are given as mean \pm SEM. The 3 genotypes were compared by 1-way ANOVA followed by Tukey's procedure. Where indicated, differences were analyzed using 2-tailed Student's $t$ test.

\section{Acknowledgments}

The authors are grateful to Randy Thresher and Kimberly Kluckman for injection of ES cells into the mouse blastocysts, Michael Chua for $\mathrm{Ca}^{2+}$ imaging, Jackie Kylander for echocardiography and electrocardiography, Katharine Thompson for histological analysis, Hyung-Suk Kim for RNA analysis, Johannes Backs and Eric Olson for providing GST-HDAC fusion proteins, and Daniel A. Pasek, Kelly E. Evans, and T. Roice Fulton for preparing and analyzing membrane preparations. Support of NIH grants HL073051 and AR018687 (to G. Meissner) and HL49277 and HL71266 (to O. Smithies) is gratefully acknowledged.

Received for publication June 26, 2006, and accepted in revised form February 13, 2007.

Address correspondence to: Gerhard Meissner, Department of Biochemistry and Biophysics, University of North Carolina at Chapel Hill, Chapel Hill, North Carolina 27599-7260, USA. Phone: (919) 966-5021; Fax: (919) 966-2852; E-mail: meissner@med.unc.edu.
1. Maier, L.S., and Bers, D.M. 2002. Calcium, calmod-
ulin, and calcium-calmodulin kinase II: heart-
beat to heartbeat and beyond. J. Mol. Cell. Cardiol. 34:919-939

2. Saimi, Y., and Kung, C. 2002. Calmodulin as an ion channel subunit. Annu. Rev. Physiol. 64:289-311.
3. Tang, W., Sencer, S., and Hamilton, S.L. 2002. Calmodulin modulation of proteins involved in excitation-contraction coupling. Front. Biosci. 
7:d1583-d1589.

4. Anderson, M.E. 2004. Calmodulin kinase and L-type calcium channels; a recipe for arrhythmias? Trends. Cardiovasc. Med. 14:152-161.

5. Wehrens, X.H., Lehnart, S.E., and Marks, A.R. 2005. Intracellular calcium release and cardiac disease. Annu. Rev. Physiol. 67:69-98.

6. Simmerman, H.K.B., and Jones, L.R. 1998. Phospholamban: protein structure, mechanism of action, and role in cardiac function. Physiol. Rev. 78:921-947.

7. Fill, M., and Copello, J.A. 2002. Ryanodine receptor calcium release channels. Physiol. Rev. 82:893-922.

8. Meissner, G. 2004. Molecular regulation of cardiac ryanodine receptor ion channel. Cell Calcium 35:621-628

9. Franzini-Armstrong, C., and Protasi, F. 1997. Ryanodine receptors of striated muscles: a complex channel capable of multiple interactions. Physiol. Rev. 77:699-729.

10. Yamaguchi, N., Xu, L., Pasek, D.A., Evans, K.E., and Meissner, G. 2003. Molecular basis of calmodulin binding to cardiac muscle $\mathrm{Ca}^{2+}$ release channel (ryanodine receptor). J. Biol. Chem. 278:23480-23486.

11. Xu, L., and Meissner, G. 2004. Mechanism of calmodulin inhibition of cardiac sarcoplasmic reticulum $\mathrm{Ca}^{2+}$ release channel (ryanodine receptor). Biophys. J. 86:797-804.

12. Nakagawa, O., et al. 1995. Rapid transcriptional activation and early mRNA turnover of brain natriuretic peptide in cardiocyte hypertrophy. Evidence for brain natriuretic peptide as an "emergency" cardiac hormone against ventricular overload. J. Clin. Invest. 96:1280-1287.

13. Dorn, G.W., 2nd, Robbins, J., Ball, N., and Walsh, R.A. 1994. Myosin heavy chain regulation and myocyte contractile depression after LV hypertrophy in aortic-banded mice. Am. J. Physiol. 267:H400-H405.

14. Rockman, H.A., et al. 1991. Segregation of atrialspecific and inducible expression of an atrial natriuretic factor transgene in an in vivo murine model of cardiac hypertrophy. Proc. Natl. Acad. Sci. U. S. A. 88:8277-8281.

15. Sutko, J.L., Airey, J.A., Welch, W., and Ruest, L. 1997. The pharmacology of ryanodine and related compounds. Pharmacol. Rev. 49:53-98.

16. Persechini, A., and Cronk, B. 1999. The relationship between the free concentrations of $\mathrm{Ca}^{2+}$ and $\mathrm{Ca}^{2+}$-calmodulin in intact cells. J. Biol. Chem. 274:6827-6830.

17. Wu, X., and Bers, D.M. 2007. Free and bound intracellular calmodulin measurements in cardiac myocytes. Cell Calcium. 41:353-364.

18. Backs, J., and Olson, E.N. 2006. Control of cardiac growth by histone acetylation/ deacetylation. Circ. Res. 98:15-24.

19. Backs, J., Song, K., Bezprozvannaya, S., Chang, S., and Olson, E.N. 2006. CaM kinase II selectively signals to histone deacetylase 4 during cardio- myocyte hertrophy. J. Clin. Invest. 116:1853-1864. doi:10.1172/JCI27438.

20. Molkentin, J.D. 2000. Calcineurin and beyond: cardiac hypertrophic signaling. Circ. Res. 87:731-738.

21. Wilkins, B.J., et al. 2004. Calcineurin/NFAT coupling participates in pathological, but not physiological, cardiac hypertrophy. Circ. Res. 94:110-118.

22. Yang, J., et al. 2000. Independent signals control expression of the calcineurin inhibitory proteins MCIP1 and MCIP2 in striated muscles. Circ. Res. 87:E61-E68.

23. Halling, D.B., Aracena-Parks, P., and Hamilton, S.L. 2005. Regulation of voltage-gated $\mathrm{Ca}^{2+}$ channels by calmodulin [erratum 2006, 318:er1]. Sci. STKE. 315:re15.

24. Wu, Y., Colbran, R.J., and Anderson, M.E. 2001. Calmodulin kinase is a molecular switch for cardiac excitation-contraction coupling. Proc. Natl. Acad. Sci. U. S. A. 98:2877-2881.

25. Balshaw, D.M., Yamaguchi, N., and Meissner, G. 2002. Modulation of intracellular calcium-release channels by calmodulin. J. Membr. Biol. 185:1-8.

26. Bers, D.M. 2004. Macromolecular complexes regulating cardiac ryanodine receptor function. J. Mol. Cell. Cardiol. 37:417-429.

27. Wehrens, X.H.T., Lehnart, S.E., Reiken, S.R., and Marks, A.R. 2004. $\mathrm{Ca}^{2+} /$ calmodulin-dependent protein kinase II phosphorylation regulates the cardiac ryanodine receptor. Circ. Res. 94:E61-E70.

28. Frey, N., and Olson, E.N. 2003. Cardiac hypertrophy: the good, the bad, and the ugly. Annu. Rev. Physiol. 65:45-79.

29. Jones, L.R., et al. 1998. Regulation of $\mathrm{Ca}^{2+}$ signaling in transgenic mouse cardiac myocytes overexpressing calsequestrin. J. Clin. Invest. 101:1385-1393.

30. Sato, Y., et al. 1998. Cardiac-specific overexpression of mouse cardiac calsequestrin is associated with depressed cardiovascular function and hypertrophy in transgenic mice. J. Biol. Chem. 273:28470-28477.

31. Terentyev, D., et al. 2003. Calsequestrin determines the functional size and stability of cardiac intracellular calcium stores: mechanism for hereditary arrhythmia. Proc. Natl. Acad. Sci. U. S. A. 100:11759-11764.

32. Gruver, C.L., DeMayo, F., Goldstein, M.A., and Means, A.R. 1993. Targeted developmental overexpression of calmodulin induces proliferative and hypertrophic growth of cardiomyocytes in transgenic mice. Endocrinology. 133:376-388.

33. Zhang, T., et al. 2003. The deltaC isoform of CaMKII is activated in cardiac hypertrophy and induces dilated cardiomyopathy and heart failure. Circ. Res. 92:912-919.

34. Balshaw, D.M., Xu, L., Yamaguchi, N., Pasek, D.A., and Meissner, G. 2001. Calmodulin binding and inhibition of cardiac muscle calcium release channel (ryanodine receptor). J. Biol. Chem. 276:20144-20153.

35. Stern, M.D., and Cheng, H. 2004. Putting out the fire: what terminates calcium-induced calcium release in cardiac muscle? Cell Calcium. 35:591-601.

36. Fabiato, A. 1985. Time and calcium dependence of activation and inactivation of calcium-induced release of calcium from the sarcoplasmic reticulum of a skinned canine cardiac Purkinje cell. J. Gen. Physiol. 85:247-289.

37. Luo, C.H., and Rudy, Y. 1994. A dynamic model of the cardiac ventricular action potential. I. Simulations of ionic currents and concentration changes. Circ. Res. 74:1071-1096.

38. Sobie, E.A., Dilly, K.W., dos Santos Cruz, J., Lederer, W.J., and Jafri, M.S. 2002. Termination of cardiac $\mathrm{Ca}^{2+}$ sparks: an investigative mathematical model of calcium-induced calcium release. Biophys. $J$. 83:59-78.

39. Stern, M.D., Pizarro, G., and Rios, E. 1997. Local control model of excitation-contraction coupling in skeletal muscle. J. Gen. Physiol. 110:415-440.

40. George, C.H., Jundi, H., Thomas, N.L., Fry, D.L., and Lai, F.A. 2007. Ryanodine receptors and ventricular arrhythmias: emerging trends in mutations, mechanisms and therapies. J. Mol. Cell. Cardiol. 42:34-50.

41. Postma, A.V., et al. 2002. Absence of calsequestrin 2 causes severe forms of catecholaminergic polymorphic ventricular tachycardia. Circ. Res. 91:e21-e26.

42. Knollmann, B.C., et al. 2006. Casq2 deletion causes sarcoplasmic reticulum volume increase, premature $\mathrm{Ca}^{2+}$ release, and catecholaminergic polymorphic ventricular tachycardia. J. Clin. Invest. 116:2510-2520. doi:10.1172/JCI29128.

43. Lahat, H., et al. 2001. A missense mutation in a highly conserved region of CASQ2 is associated with autosomal recessive catecholamine-induced polymorphic ventricular tachycardia in Bedouin families from Israel. Am. J. Hum. Genet. 69:1378-1384.

44. Viatchenko-Karpinski, S., et al. 2004. Abnormal calcium signaling and sudden cardiac death associated with mutation of calsequestrin. Circ. Res. 94:471-477.

45. Caron, K.M., et al. 2004. Cardiac hypertrophy and sudden death in mice with a genetically clamped renin transgene. Proc. Natl. Acad. Sci. U. S. A. 101:3106-3111

46. Xu, L., Wang, Y., Gillespie, D., and Meissner, G. 2006. Two rings of negative charges in the cytosolic vestibule of type- 1 ryanodine receptor modulate ion fluxes. Biophys. J. 90:443-453.

47. Martonosi, A., and Feretos, R. 1964. Sarcoplasmic reticulum. I. The uptake of $\mathrm{Ca}^{2+}$ by sarcoplasmic reticulum fragments. J. Biol. Chem. 239:648-658.

48. Xu, L., Tripathy, A., Pasek, D.A., and Meissner, G. 1999. Ruthenium red modifies the cardiac and skeletal muscle $\mathrm{Ca}^{2+}$ release channels (ryanodine receptors) by multiple mechanisms. J. Biol. Chem. 274:32680-32691.

49. Schoenmakers, T.J., Visser, G.J., Flik, G., and Theuvenet, A.P. 1992. CHELATOR: an improved method for computing metal ion concentrations in physiological solutions. BioTechniques. 12:870-879. 